Supplement of Hydrol. Earth Syst. Sci., 22, 53-70, 2018

https://doi.org/10.5194/hess-22-53-2018-supplement

(c) Author(s) 2018. This work is distributed under

the Creative Commons Attribution 4.0 License.

(c) (1)

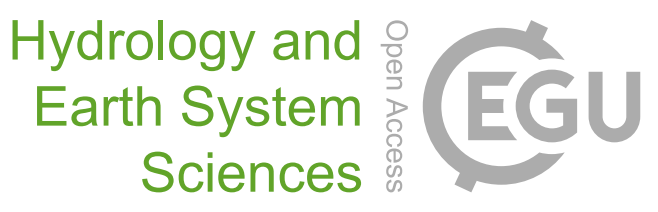

Supplement of

\title{
Shallow water table effects on water, sediment, and pesticide transport in vegetative filter strips - Part 1: nonuniform infiltration and soil water redistribution
}

\section{Rafael Muñoz-Carpena et al.}

Correspondence to: Rafael Muñoz-Carpena (carpena@ufl.edu)

The copyright of individual parts of the supplement might differ from the CC BY 4.0 License. 


\section{Supplementary materials}

S1. Program distribution.

Free open source code, documentation and sample applications can be downloaded from

http://abe.ufl.edu/carpena/software/swingo.shtml 


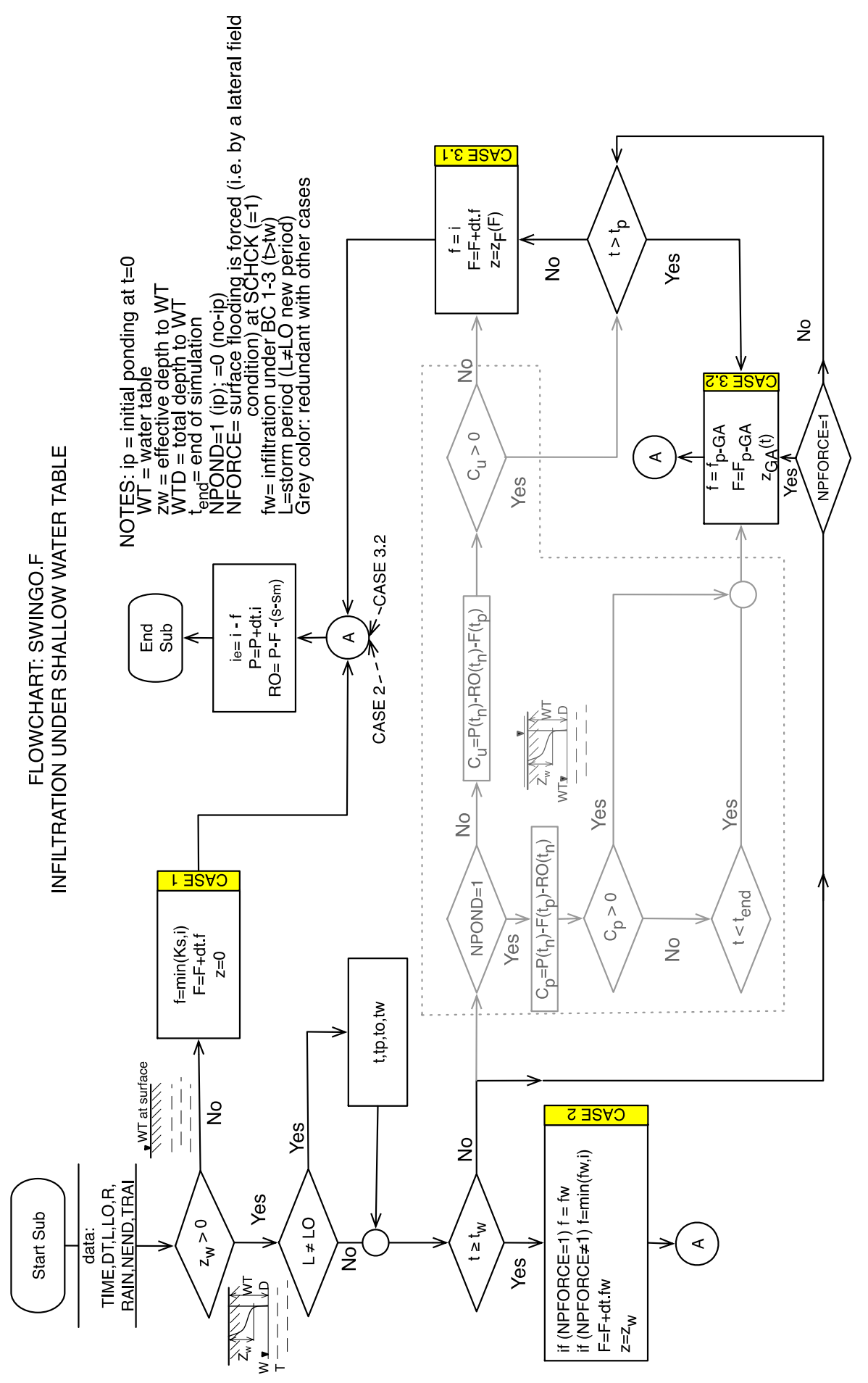

